\title{
Arguments for a Privative $L$ Tone in Northern Tepehuan
}

\author{
Carlos Gil Burgoin \\ Universidad Autónoma de Baja California
}

\section{Introduction}

Only a small set of languages have been properly characterized as privative tone systems, i.e., a language where the tonal contrast is better characterized as presence vs. absence of a tonal specification (Hyman $2000)^{1}$, instead of the opposition of two different tone specifications. Some authors noted also that privative (or unary) systems with one high tone are more common than systems with a low tone (Hyman 2000; Yip 2002). This paper argues for an analysis of Northern Tepehuan (Uto-Aztecan, Mexico) as just that; a language with a tonal system of one single low $(\mathrm{L})$ tone, providing evidence which is different from Hyman's proposal -constraints on morpho-phonological distribution, surface distribution, tonal processes [spreading, deletion-, such as word stress assignment and placement of intonational peak. Strict definitions of tone and stress are assumed, and the proposal is modeled in a hierarchy of OT constraints. It is also shown that this analysis better explains the word-level prosody of the language as compared to an alternative privative high (H) system.

Northern Tepehuan (NTep) has an enigmatic prosodic pattern at word level. Since Bascom (1959), NTep has been referred to as a tonal language, but he provided little (usually incidental) phonetic, distributional or contrastive detail. Woo (1970) developed Bascom's equipollent (H, L) proposal into a complex rule-based model which, nonetheless, fails to answer basic questions like do these tones indubitably contrast?, what "tonal" patterns are possible?, are the different patterns in words really tonal patterns or they can be better understood as a combination of other factors, such as stress or vowel length? In this regard, Bascom (1959) depicted a language where stress "fluctuates freely", despite the fact that once a considerable group of words are observed (e.g. Bascom \& Molina 1998) it is evident that some kind of single prominence occurs always in the first or second syllable. Bascom (1982: 272) claimed some years later that stress is predicted from tone, although never explained how. On the other hand, Kim (1997) claimed the opposite, that tone is predicted from stress, but failed to recognize that some pairs of words really seem to contrast by tone.

Considering the obscure synthesis yielded by previous accounts, this study presents a summarized first approach to a systematic account of the word-level prosodic system of NTep that fundamentally answers the following questions:

i. Assuming that there is a tonal contrast, what specification(s) underly NTep pitch contrast? Is the system /H/ vs /L/, /H/ vs. / $\varnothing /$ or /L/ vs. / $\varnothing /$ ?

ii. How is stress assigned in NTep?

iii. What is the relation between stress and tone in NTep?

After providing some basic data for the language and definitions in sections 3 and 4, the structure of the argumentation is as follows: section 4 presents arguments for NTep as a tonal system based on classification and contrast of disyllabic words; section 5 reviews the assignment of stress in different word classes and the

\footnotetext{
${ }^{1}$ It is not straightforward how common privative tonal systems are as the most thorough surveys carried out on tonal systems usually do not consider a specific class for privative systems (see Maddieson 2013; Gordon 2016). In those works, many of the languages that are classified as privative tonal systems by Hyman $(2000 ; 2018)$ appear as simple systems, forming a group with equipollent $(\mathrm{H}, \mathrm{L})$ systems. 
problems posed by this phenomenon; section 6 provides a solution for the problem of stress assignment that implies the interaction of stress and tone, and the characterization of the tonal system as L privative; section 7 introduces the inadequacies of proposing an alternative $\mathrm{H}$ privative system; section 8 presents the conclusions.

\section{Language and data}

Northern Tepehuan (NTep) is a language from southern Chihuahua, Mexico, with around 9000 speakers (Saucedo 2004; Carrillo 2013). The language belongs to the Tepiman branch of the Uto-Aztecan family (Miller 1984). It has received moderate research attention from linguists and lacks linguistic description at many levels, especially at the phonological level (see Gil Burgoin 2020 for a critical review of the bibliography on NTep). This study presents data gathered thanks to two female speakers from the Tupuri village, in Baborigame, Chihuahua.

\section{Strict definitions}

In this paper I stick to the view on word-prosodic typology presented by Hyman $(2006,2009)$ where the word-level prosodic system of any language can be described in terms of only two parametric categories, stress and tone, explicitly rejecting notions such as "pitch-accent language". The complexity presented by languages such as Japanese or Basque is explained by a low tonal density -a non-prototypical but true tonal system-, the presence or absence of stress and the possibility of interaction between the two categories.

In this view, the definition of stress provided by Hyman (2006) is a word-level prominence that shows these traits:

a. Culminativity. At most one stress per word

b. Obligatoriness. At least one stress per word.

On the other hand, tone is understood as any pitch indication present at the lexical representation of at least some morphemes (Yip 2002; Hyman 2006) independently of how common these indications are in the lexicon or of other properties as culminativity or obligatoriness. Additionally, contrastive vowel length $(C V L)$ refers here to any indication of relative duration of a vowel present at the lexical representation of morphemes.

\section{Prosodic categories in Northern Tepehuan}

In this section the phonological relevance of tone is established via the contrast and classification of disyllabic words. The further analysis concluding that the system is L privative is based on these claims, as well as in the problem posed by another prosodic category, stress, which is presented in section 5 .

4.1 CVL The prosodic classification of disyllabic words entails the observation of CVL. This is the most straightforward phonological prosodic category at word level in NTep. The examples in (1) show that vowel duration is contrastive in NTep.

$$
\begin{array}{ll}
\text { a. ['íf:i] } & \text { 'cropland' } \\
\text { b. ['t: } f i] & \text { 'quantity' }
\end{array}
$$

The distribution of long vowels is highly restricted: there is maximally one long vowel per word and, when it appears, it can only be located in the first syllable of the word. Thus, a disyllabic word can be either $[\mathrm{V} . \mathrm{V}]$ with only short vowels or [V:.V] with a long vowel followed by a short vowel.

4.2 Tone An observation of a 1200-entries lexical base shows that disyllabic words fall into two different patterns according to their pitch contour: either the word pitch is [H.L] or [L.H]. Examples are shown in (2); note that in both cases stress falls in the first syllable.
a. ['ú:Ki ]
H.L
'grandmother'
b. ['ù:fí] L.H 'wood 
If we combine the aforementioned CVL patterns with the two possible pitch contours, three clear patterns emerge (see Gil \& Carrillo 2019). As exemplified below, [V.V] disyllabic words always have a [H.L] contour (3a) whereas [V:.V] presents either [H.L] (3b) or [L.H] (3c). Of the three possible patterns here, tonal contrasts are established between ( $3 b)$ and (3c) words -as in the minimal pair of 'needle' vs. 'follow'- where the only formal difference is the pitch contour, adjusting therefore to a strict definition of tone $^{2}$. It is important to observe that truly incontrovertible tonal contrasts are only possible between disyllabic words in NTep -in polysyllabic words contrast can be attributed to a number of reasons, not necessarily pitch-. In Figure 1 we observe the typical pitch trajectory of $3 b$ (H.L) and 3c (L.H) patterns, according to measurements of F0 performed on 265 tokens of HL-patterned words and 427 tokens of LH-patterned words.
a. ['bá.vì] [V.V]
b. ['ó:.ji $] \quad[\mathrm{V}: \mathrm{V}]$
H.L 'beans'
c. ['ò:.jí] $[\mathrm{V}: \mathrm{V}]$
H.L 'needle'
L.H 'follow'

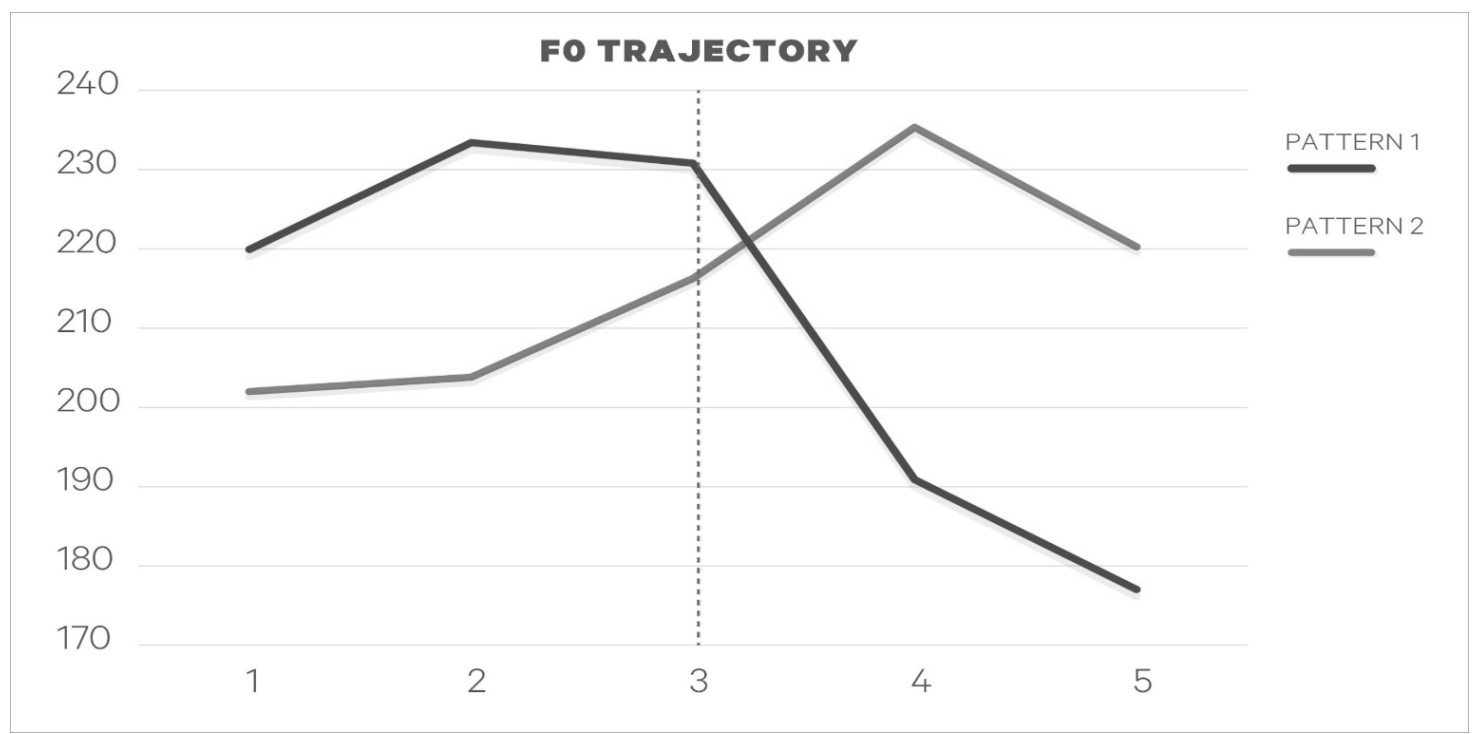

Figure 1. Typical F0 trajectory $(\mathrm{Hz})$ of $3 b$ patter $(\mathrm{HL})$ and $3 \mathrm{c}$ pattern $(\mathrm{LH})$

Until this point it has been shown that NTep has contrasts solely based on pitch, i.e., it is a tonal language. However, the main question that emerges from such generalizations is, which tonal specifications underly these pitch patterns? We cannot simply assume that these provisional phonetic tags correspond to an equipollent L vs $\mathrm{H}$ system; rather, we must seek phonological arguments supporting systematic behaviors for each specification. Another important question concerning the alignment of pitch peak arises; why are the L.H-patterned words the only words in the language where the stress is not aligned with the pitch peak of the word? We will return to these questions later.

\section{Stress assignment}

5.1 General mechanism NTep stress is generally predictable from the number of syllables of the word and from syllable weight, although there are a number of relevant exceptions. The stress mechanism can be described in two different stages. The first stage observes disyllabic words, which, as stated above, are always stress-initial. In these cases, stress is independent of syllable weight or other factors such as pitch-contour, as

\footnotetext{
${ }^{2}$ Stress is initial in all disyllabic words. Gil Burgoin (2018) provides arguments for considering that vowel quality in the formant space, intensity and duration are relatively stable correlates of stress in NTep. Thus, it is possible to not depend on pitch to locate stress placement which is convenient to provisionally get rid of a potential confusion between stress and tone-whose natural correlate is pitch-. However, as it will be shown, in many cases pitch is also a correlate of stress in NTep.
} 
in the examples of (3). A typologically-informed means of formalizing this generalization (Kager 2004) is the statement in (4).

Stress is never final

The second stage treats polysyllabic words -words with three, four, five or more syllables-. These words also comply with (4), but as there is room for placing the stress in different syllables, they have additional requirements. The mechanism of assignment can be formulated in the following terms:

i. stress falls on the first heavy $\boldsymbol{\sigma}$

ii. otherwise it falls on the second $\sigma$

This mechanism can be observed operating in the words in (6). When the first syllable has a long vowel (a), a consonant coda (b), or a glide coda, the stress is initial, but when the word only has short vowels the stress falls on the second (d). Note that when there are two heavy syllables, as in (c), stress falls on the first of them.
a. ['ú:rugi] 'bird'
b. ['táf'kaKi] 'tortilla'

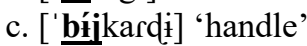
d. [ba'tópa] 'fish'

The examples of (6) can be said to be morphologically simple polysyllabic words. Suffixed polysyllabic words that come from disyllabic words provide further evidence for the correctness of (5). We know that disyllabic words belong to three prosodic patterns and they are always stress-initial but, what happens to stress when the disyllabic word is lengthened by adding a suffix? The analysis with possessive suffix 'di' shows that the placement of stress is determined by the pattern that the base word belongs to: $3 \mathrm{a}, 3 \mathrm{~b}$ or $3 \mathrm{c}$. We will focus first on $3 \mathrm{a}$ and $3 \mathrm{~b}$ base words: the ones with [H.L] pitch contour. In the examples provided in (7) we observe that (6) correctly predicts where the stress is placed for both patterns: polysyllabic words from pattern $3 b$ have an initial heavy syllable that attracts stress -stress appears on the same vowel as in the disyllabic form-, whereas words from pattern 3 a only have short vowels, thus producing a movement of stress and placing it on the second syllable.
a. Pattern 3a

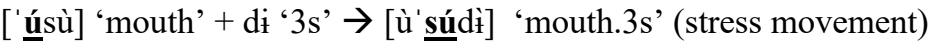
b. Pattern 3b
[' $\underline{\text { nó: }}: \mathbf{i}]$ 'brother in law' + di $\rightarrow$ [' nó:fìdi] 'brother-in-law.3s'

5.2 Exception 1 As illustrated in (8), polysyllabic words formed through suffixation of disyllabic words from pattern $3 \mathrm{c}$ do not conform to (6), in that stress does not fall on the heavy syllable - the first syllable- but on the second syllable instead. The suffixation process produces the same effect of stress movement as in the pattern 3a, i.e., stress does not appear on the same vowel in disyllabic and polysyllabic words.

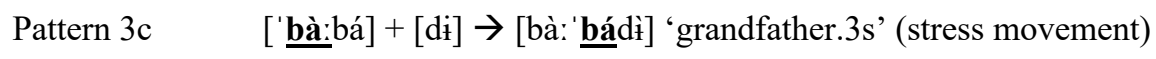

5.3 Exception 2 The reach of (6) also is affected by a number of morphologically simple polysyllabic words which have a first unstressed heavy syllable. In these cases, the heavy syllable is formed by a long vowel.

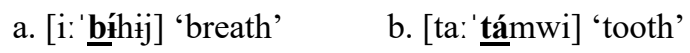

5.4 Summarizing stress mechanism and problems The proposed modelling of the general stress mechanism in NTep involves the activity of the three OT constraints formulated in (10) in the hierarchization of (11). This hierarchy guarantees that stress is never final and, whenever possible, stress is located on the left margin of a foot -the second syllable- except when a heavy syllable attracts stress. 

a. NON-FINALITY
Stress is never final
b. IAMBIC-RHYTHM
Feet are $(\mathrm{LH})$ or $(\mathrm{H})$
c. STRESS-TO-Weight
Heavy syllables are stressed

NON-FINALITY $>>$ IAMBIC-RHYTHM $>>$ STRESS-TO-WEIGHT

However, the few problems presented by the exceptions need further elements to be resolved. The analysis must find a plausible reason for the following questions:

(12) a. Why the words in (8) and (9) do not align the stress with a heavy syllable?

b. Why the words with $3 \mathrm{c}$ pattern do not align stress and pitch peak?

\section{L privative tone}

This work proposes that a lexical $\mathrm{L}$ tone is the solution for (12) two queries. A lexical /L/ tone in the long vowel of 3c pattern words could explain why stress is not allowed to attach to this heavy syllable. DeLacy (2002) shows that in many languages stress always seeks to match the more prominent sites, and a syllable with a lexical low is not one if these sites. Stress will then land on the second syllable even if this contradicts some constraints of the general stress mechanism (see 13, where $\mathrm{b}$ is unattested). Then we also propose that the constraint in (14) is high-ranked in the language, although ranked below NON-FINALITY.

a.

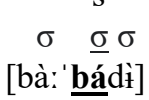
L

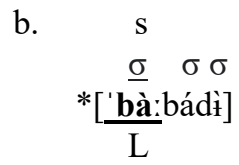

$\mathrm{L}$

*Align(Head/Low) Stress is never aligned with a low tone

A phonological low tone could also explain why the pitch peak is displaced from stress in disyllabic pattern 3c words, having an LH contour. This peak corresponds to an intonational $\mathrm{H}^{*}$ tone that normally is attached to a stressed syllable in any other word -it corresponds to the $\mathrm{H}$ in patterns $3 \mathrm{a}$ and $3 \mathrm{~b}-$, but not here. In $3 \mathrm{c}$ pattern words, the presence of lexically-specified $\mathrm{L}$ prevents any other tonal specification to be docked, so $\mathrm{H}$ falls in the following syllable. Additionally, a Low tone is enough to explain the contrast between (3b) and ( $3 \mathrm{c})$, so (3b) is a toneless word and (3c) a low-toned word. Compare the placement of intonational $\mathrm{H}^{*}$ in (15) in words with pattern $3 \mathrm{a}$-toneless- and words with pattern $3 \mathrm{c}$.

$$
\begin{aligned}
& \text { a. } \quad \underline{\sigma} \sigma \\
& \text { ['ú: } \frac{\mathbf{u}}{\mathrm{H}^{*}}
\end{aligned}
$$

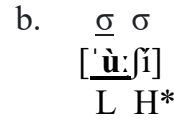

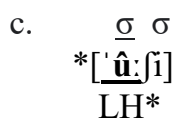

\section{Alternative: /H/ tone}

Whereas L tone is necessary to explain the patterns of stress, and sufficient to explain the pitch contrast, the previously-proposed lexical $\mathrm{H}$ tone introduces formal problems and unjustified features. For instance, previously proposed $/ \mathrm{H} /$ lacks any specific effect not explained by stress. Although the final peak in $3 \mathrm{c}$ words could be explained by $/ \mathrm{H} /$ in the final syllable, it would imply asymmetries in TBUs: $\boldsymbol{\sigma}$ or $\boldsymbol{\mu}$ ? Nonetheless, the $/ \mathrm{H} /$ previously proposed would come diachronically from $\mathrm{V} ?(\mathrm{~V})$ : if the system is truly privative, where are the $/ \mathrm{H} /$ ?

\section{Summary}

Northern Tepehuan is a tonal language with just one lexical tone -low tone- and is therefore a privative tonal system. $\mathrm{L}$ tone is sufficient to explain the pitch contrasts in the language and also necessary to explain the "inconsistencies" of stress assignment. Stress is normally predictable from the size of the word, from syllable-weight, and is cued by a $\mathrm{H}^{*}$ intonational tone. Nonetheless, in words that do not obey the Stress-to- 
Weight constraint, it could be argued that stress is displaced from the heavy syllable by virtue of a highranked *Align(Head/Low) constraint that prohibits the placement of stress on a syllable with a lexical $\mathrm{L}$. The $\mathrm{L}$ tone also explains why the $\mathrm{H}^{*}$ intonational tone can be displaced from stressed syllables.

\section{References}

Bascom, Burton. 1959. Tonomechanics of Northern Tepehuan. Phonetica 4. 71-88.

Bascom, Burton. 1982. Northern Tepehuan, in Langacker, Ronald (ed.), Studies in Uto-Aztecan Grammar. Uto-Aztecan Grammatical Sketches 3, 267-393. Dallas: Summer Institute of Linguistics/University of Texas at Arlington.

Bascom, Burton \& Molina, Gregorio. 1998. Diccionario Tepehuán de Baborigame. (Available online in https://www.sil.org/resources/archives/35910)

Carrillo, Araceli. 2013. Formación de palabras en tepehuano del norte (odami). Hermosillo: Universidad de Sonora (MA dissertation).

De Lacy, Paul. 2002. The Interaction of Tone and Stress in Optimality Theory, Phonology 19: 1-32.

Gil, Carlos. 2018. Unraveling prosodic categories in Northern Tepehuan. Talk at Sound Systems of Latin America (Amherst).

Gil, Carlos. 2020. Un balance crítico de los estudios lingüísticos del ódami (tepehuano del norte): De Rinaldini a la contribución de los hablantes nativos. Cuadernos de Lingüística de El Colegio de México 7, e195. doi: 10.24201/clecm.v7i0.195.

Gil, Carlos \& Carrillo, Araceli. 2019. Marcación prosódica de los enunciados interrogativos absolutos en tepehuano del norte, in Z. Estrada, m. Tubi y A. Álvarez (eds.), Estudios de lenguas amerindias 4. Escenario actual de la investigación sobre lenguas yuto-aztecas. Homenaje a Jane H. Hill, 105-136. Hermosillo: Universidad de Sonora.

Gordon, Matthew. 2016. Phonological Typology. Oxford: Oxford University Press.

Hyman, Larry. 2000. Privative tone in Bantu. Talk at the Symposium on Tone (Tokyo). (Available online at http://www.linguistics.berkeley.edu/ hyman/Privative_Tone_Tokyo_A4.pdf

Hyman, Larry. 2006. Word-prosodic typology. Phonology $23.22 \overline{5}-57$.

Hyman, Larry. 2009. How (not) to do phonological typology: the case of pitch-accent. Language Sciences 31: 213-238.

Hyman, Larry. 2018. Towards a Typology of Tone System Change, in Kubuzono, Haruo \& Giriko, Mikio. Tonal Change and Neutralization. Boston/Berlin: deGruyter, 203-22.

Kager, René. 2004. Optimality Theory. Cambridge: Cambridge University Press.

Kim, Michael Jinhwa. 1997. Tonal Predictability From Metrical Structure in Northern Tepehuan. Proceedings of the West Coast Conference in Formal Linguistics 15. 257-272

Maddieson, Ian. 2013. Tone, in Matthew S. Dryer and Martin Haspelmath (eds), The World Atlas of Language Structures Online. Leipzig: Max Planck Institute for Evolutionary Anthropology. (Available online at http://wals.info/ chapter/13).

Miller, Wick. 1984. The Classification of the Uto-Aztecan Languages Based on Lexical Evidence. International Journal of American Linguistics 50 (1). 1-24.

Saucedo Sánchez de Tagle, Eduardo Rubén. 2004. Tepehuanes del Norte. México: CDI /PNUD

Yip, Moira. 2002. Tone. Cambridge: Cambridge University Press.

Woo, Nancy. 1970. Tone in Northern Tepehuan. International Journal of American Linguistics 36 (1).18-30. 